\title{
Review Paper: The Necessity to Establish Health, Safety and Environment Management Major at the University of Social Welfare and Rehabilitation Sciences
}

\author{
Mehrdad Farrokhi' ${ }^{1}$ (D) Hamidreza Khankeh ${ }^{1}$, Mohsen Poursadeqiyan ${ }^{2 *}$ (D) \\ 1. Research Center in Emergency and Disaster Health, University of Social Welfare and Rehabilitation Sciences, Tehran, Iran. \\ 2. Health Sciences Research Center, Torbat Heydariyeh University of Medical Sciences, Torbat Heydariyeh, Iran.
}

Cftation: Farrokhi M, Khankeh H, Poursadeqiyan M. The Necessity to Establish Health, Safety, and Environment Management Major at the University of Social Welfare and Rehabilitation Sciences. Health in Emergencies and Disasters Quarterly. 2019; 4(3):119126. http://dx.doi.org/10.32598/hdq.4.3.119

: http://dx.doi.org/10.32598/hdq.4.3.119

Article info:

Received: 21 Sep 2018

Accepted: 12 Jan 2019

Available Online: 01 Apr 2019

\section{Keywords:}

Safety, Rehabilitation, Welfare, Environment, Manegment, Scocial health

\begin{abstract}
Researchers have already highlighted the safety and health issues in workplaces. The necessity of these issues and their close relations to the environment have more transparently called for the management control of three critical dimensions of Health, Safety, and the Environment (HSE). Furthermore, following the rapid development of technology and the complexity of the activities tailored to the needs of companies and industries, a set of guidelines called HSE was developed to minimize the damages to human, equipment, and environment. Therefore, today presenting the academic education of HSE management system as a university Major, especially in universities affiliated with the Ministry of Health and Medical Education, like the University of Social Welfare and Rehabilitation Sciences seems necessary. In particular, USWR, besides rendering health, treatment, and rehabilitation services is a provider of the third level of the health system. Therefore, considering the importance of the issue, approximately a quarter century history of USWR establishment, and the fundamental nature of the health and prevention areas, this university attempted to use the comprehensive view of HSE management, to complete its activities in the field of Welfare and Rehabilitation Sciences. This paper aimed to investigate the necessity of establishing the HSE management Major at the USWR. The investigation was conducted using library review research, field study, community wisdom, and expert knowledge. The obtained data and results suggested that the USWR and its subsidiary centers recognized establishing HSE Major as beneficial in expanding research and science fields in rehabilitation services. It may also help pay more attention to the elderly, disabled, and children, both in terms of occupational hazards, and the general safety and various levels of life. Further in-depth research in these areas can ultimately help improve the wellbeing of all society members.
\end{abstract}




\section{Introduction}

ollowing the advancement of the industry, the entry of machinery into the lives of F people, the increased role of equipment and devices in working processes, and more interaction of humans with the industrial environments, organizations are constantly facing with novel challenges in terms of Health, Safety and the Environment (HSE) matters [1].

Organizations spend billions of dollars annually to compensate human and machinery losses caused by work-related accidents and illnesses as well as to eliminate the environmental pollution caused by their activities. Industrial and production units are the country's economic engines that play a significant role in the national economy in sectors of employment, production, exports, and the promotion of national productivity, so human and machinery losses are considered to be significant obstacles to development [2].

Therefore, it is logical for organizational managers to not only consider management aspects such as quality, financials, technology, production, and so on but also the dimensions of occupational HSE because the general improvement of the organization is not possible without these aspects [3]. In this regard, HSE has been developed in response to the needs of the companies and industries. The primary purpose of developing this structure was to minimize injuries to humans, equipment, and the environment [4].

In other words, to save and improve organizations, human resources, environmental sustainability; prevent damages to equipment and facilities; and to end all current concerns, HSE science was developed in the industry. Indeed, the HSE system is a management tool for controlling and improving HSE in all industrial development or organizational development programs. In each workplace, the HSE management system should be tailored to the workplace and type of activity and incidents. The primary purpose of developing this system was to minimize injuries to humans, equipment, and the environment [5].

Broadly speaking, the HSE is a system that synergistically integrates and coordinates the human resources and equipment to create a healthy, pleasant and vibrant workplace, without any accident, damages, and losses [6]. In other words, the HSE management system is part of a general current management system in the organization and, like other control systems, follows the PDCA
(Plan-Do-Check-Act) cycle [3]. All pioneer oil companies in the world, such as BP, Shell, Total, ADNOC, Iran's Oil Ministry, etc., have a model of HSE management system [7].

To put it differently, this important matter is only possible through the passing and execution of transparent rules and regulations, as well as a managerial structure for controlling processes [8]. The success of this system needs the involvement and engagement of all employees in the implementation of HSE requirements; in other words, the high performance of staff. In this way, human resources and their proper training and awareness of the HSE and its importance are considered as the most critical factors influencing HSE issue (safety, health, and environment) [1].

In addition, during the past decades, investment in staff training has been increasing, and organizations have emphasized more on the development of educational activities and the provision of learning opportunities for all employees at different levels. Organizations consider the training and development of human resources one of their most vital tasks, for improving organizational and human resources [9].

Other issues that highlight the importance of training of employees are the appropriate use of human resources, quantitative and qualitative improvement of products and services, prevention of work-related incidents, organization's stability (and flexibility in the necessary cases), reduction of employee supervision and their reinforcement and improving pride $[10,11]$.

Moreover, along with scientific advantages and technological changes, organizations spent a vast amount of money for training specific skills annually; while, these expenditures do not solely prove the effectiveness of training, without measuring the employees' efficacy or the existence of an adequate feedback system. Unfortunately, in many cases, no practical system exists at all, or it is very ineffective and useless [12].

Additionally, the limited resources of organizations require a careful examination of the past work process and the quality of the training provided; therefore, the duplication of work and consumption of unnecessary costs and waste of time and the workforce should be avoided. Furthermore, the kind of training must be provided that, not only change the attitude and insight of the individuals to adapt them with the organization positively, but also be useful in the success of assigned tasks [13]. 
Therefore, it is necessary that higher education systems at universities provide community-based education that observes the needs of the society to educate skilled and knowledgeable graduates, especially in the health system, where specialized training in areas such as HSE can be very efficient $[1]$.

\section{HSE history in the world}

Since the late $20^{\text {th }}$ century, researchers paid attention to the issues of HSE in a systematic framework. In this context, the HSE Management System (HSE-MS) has been considered as an appropriate management system. Health and safety before establishing a systemic organization under the concept of HSE in the world, has been active in various industries with a history of about two centuries under one unit, and their duties have been separable from each other [5].

In this regard, occupational health is an essential part of the health of employees. It prevented the occurrence of illness in the staff by providing solely technical services and controlling the harmful factors in the workplace. It also minimized the employees' and the environment's risk-taking by creating healthy working environments. Occupational Safety and Health Administration (OSHA) organization presented the health and safety history in 1812 [14].

Following the development of environmental and occupational safety and health systems in 1996 and 1999 by the International Organization for Standardization (ISO) and the success of the establishment of the abovementioned management systems in various organizations, the oil industry sought to develop specific standards about the safety issues and professional health engineering and environmental health. In this regard, important oil companies such as Shell, BP, Total, the International Association of Oil and Gas Producers (OGP), etc. have developed a guide to the establishment and development of an HSE Management System (HSE-MS) [15].

\section{History of HSE in Iran}

In Iran, in late 2001, following to the Ministry of Oil's emphasis on the establishment of the HSE management system in the ministry, the Central Council for Safety and Fire, has opted to select and translate the HSE-MS guidelines developed by the OGP Oil and Gas Producers Association [16]. The National Refinery and Distribution of Iranian Oil Products has continued to compile HSE management policies to meet the global standards of the oil industry and to change the attitude of traditional views on safety issues in its portfolio [16].

In the short period of its activity, this system has replaced safety and fire departments protocol and had a notable performance in operational sets, despite being very young. Inspired by the HSE model, the National Iranian Oil Company has compiled this standard in its organization [16]. Thus, each of the oil company subsidiaries (i.e. the main oil, gas, and petrochemical companies, and subcontractors) has used internationally developed guidelines to implement the HSE model.

By the end of 2001, some of the country's major industries developed guidelines for the development and implementation of HSE system goals and plans. Currently, in many domestic industries, ministries and organizations, such as the Ministry of Agriculture, Ministry of Health and Medical Education, the Organization of Industries and Mines, Municipality, and so on, the HSE goals and plans are being introduced and implemented. All major oil companies in the world, such as ADNOC, BP, Shell, Total, Iran Oil Ministry, etc. have a model of HSE management system [5]. Pars Ground Data Company is among the domestic companies that have successfully deployed and implemented this system. This company offers services to drilling rigs $[17,18]$.

\section{An academic approach to HSE education}

Considering the comprehensive HSE management approach that began with the oil and gas industry, as well as the need for the deployment of management systems to guide and integrate these issues, various factories are increasingly obliged to engage in this field. In university systems, each university has also involved in this area by a specialized and unique approach. For instance, the approach of engineering universities and the Ministry of Science is definitely different, and they mainly focus on the safety and technical aspects of work [19].

Also, the approach of chemical engineering, as well as oil and gas departments, is even more different, and they mostly consider the safety approach and chemical effects on the environment and health. Additionally, in the universities affiliated with the Ministry of Health and Medical Education (MHME), the HSE management approach is based on basic disciplines such as environmental and occupational health that are significant obstacles of advances in this field [19]. 
The Necessity of establishment of HSE major at the University of Welfare and Rehabilitation Sciences

The University of Social Welfare and Rehabilitation University o Social Welfare and Rehabilitation Sciences is one of the affiliated universities to the MHME, with the mission of addressing mental health, social aspects, and rehabilitation Statute of the University o Social Welfare and Rehabilitation Sciences. It is imperative to pay attention to the safety, security, and physical and environmental health [20].

Therefore, the students should get familiar with this subject which is not only compelling but also a very constructive and appropriate decision. Mainly because the provision of professional and academic education of the HSE system as an academic major in universities, especially in the universities affiliated to the MHME, like the University o Social Welfare and Rehabilitation Sciences, is very important. USWR not only pays attention to health and rehabilitation services but provides thirdlevel health services.

Also, paying attention to the principles of HSE in the older group is more evident as we should try to sustain the independence of low-ability people, satisfy their need for entertainment, employment, and earning, as well as regarding their vulnerability to the environmental and occupational conditions. However, the need for rehabilitation and its association with the health of people with disabilities indicate the necessity to attend the well-being and social health in all age groups [21].

Considering the importance of this issue, and passing of approximately a quarter century of the establishment of the USWR, as well as the need to consider the health and prevention areas as the basis of health, this university attempted to apply the comprehensive view of HSE management, in order to complete its mission in the field of welfare and rehabilitation.

However, the services of occupational mental health were provided sporadically, and the Ergonomics Department also worked by physical and rehabilitation approaches as well as cognitive and human error and safety management and macroeconomics in this university. Moreover, the relevant groups in emergency and disasters had activities in various aspects of safety, crisis, and medical errors [22, 23].

Finally, in social welfare-related departments, the topics related to the profession (income and social factors affecting the health and labor children, etc.) and the environment were addressed. However, with the advancement of departments and their research studies, the necessity of paying attention to the health and safety management of life and workplace in the Rehabilitation Management Department was more recognized.

Moreover, the approaches of the Emergency and Disasters Health Department changed toward climate change, topics of public health, environmental health issues due to the crisis, and the need to control these issues before the crisis conditions [24-27]. Social welfare departments also attempted to develop ecological well-being disciplines, as well as assessing the occupational conditions and welfare of labor children and their conditions.

The Aging Research Department also recognized the need for further research on occupational conditions and the risks associated with the aging, like falling, and so on. Occupational therapy and psychology have activities in the field of occupational rehabilitation and the need to return to work and life of the accident-injured people.

Topics like the modification of auxiliary and rehabilitation equipment, also safety and accidents in the use of these devices, aging and its risks, and the need to pay attention to a healthy city and an elderly-friendly city have compelled the Genetic Department of this university to establish specific biological safety sections.

Nevertheless, counseling areas in the field of occupation and rehabilitation, as well as social well-being and social work, can benefit from this university Major. Ultimately, the establishment of HSE Major can enhance the integration of related activities across the 22 educational fields of the university, as well as all sections related to the Welfare Organization and Rehabilitation clinics, and will synergically improve these activities.

\section{Results}

\section{University's approach toward HSE major}

This approach considering the importance of patient's safety and rehabilitation as well as the living place, workplace, and life, include the follows:

1. The importance of patient' safety and the needs of all disabled people at any level of disability; 2 . The safety of rehabilitation equipment; 3 . Public safety and social welfare indicators.; 4. Industrial and public safety in vulnerable groups; 5. Psycho-social health in crisis and disasters; 6 . The need for occupational rehabilitation; 7. Promotion of rehabilitation management and social wel- 
fare; 8 . Promotion of nursing management and the quality of rehabilitation services; 9 . The need to modify the environment with the needs of people with disabilities; 10. The need to manage the health of workplace and life in vulnerable populations; 11. Managing environmental welfare in the entire community; 12 . The importance of connection with the mental health of society; 13 . The need to pay attention to health and prevention in rehabilitation sciences; 14 . The importance of environmental and occupational health in the fields of rehabilitation; 15 . Using the environment to help treat and rehabilitate individuals.

The purpose of establishing the HSE Major at the University of Social Welfare and Rehabilitation Sciences

1. Considering the need for further research studies and their more coordination, as well as the attention to the safety, health, and the environment in this type of studies, we decided to take steps towards this establishment; 2. It should be noted that by introducing this approach to the university, newer research contents are being opened up in many of the departments facing scarcity of research subjects; 3 . The overlook of health and prevention topics in rehabilitation and well-being;

Educational fields of the University of Welfare and Rehabilitation Sciences for HSE

1. Approximately 20 related university Faculty Members with a history of research in various areas of HSE; 2. More than 20 senior experts in environmental and occupational health, ergonomics and safety, crisis and disasters in the university, and healthcare fields in terms of patient safety; 3 . The support groups' library, the university-equipped digital library, and website; 4. Laboratories of Ergonomics, Psychology, Basic Sciences, Biomedical Genetics Departments, and so on.

Available support educational groups at the University of Social Welfare and Rehabilitation Sciences for HSE

1. Health in Emergency and Disaster (the first and only center for health research in emergencies and disasters); 2. Ergonomics (the first department of Ergonomics in the country, with eleven years of experience); 3 . Rehabilitation Management (the first department in the specialized topic); 4. Social Welfare (the first department course along with Social Welfare Management Research Center); 5. Participation of other departments of Nurs- ing (Nursing Management), Occupational Therapy, Psychology, and so on.

University backgrounds in various fields of health management, safety, ergonomics, and the environment

1. More than 100 project and theses titles related to safety, occupational health, and environmental health as a result of 20 years of investigating in research projects and theses (undirected); 2. More than 300 titles of related published articles by professors concerning health, safety, and environment; 3. Compiling and publication of more than 30 books related to fields at the university; 4. Development of several standards and technological designs and inventions; 5. Over 10 years of experiences of some related departments (Health in Emergency and Disasters, Ergonomics); 6. Over two decades of practical activities of bioenvironmental clubs; 7. Establishing the supreme safety system and environmental and energy committees.

Technologies related to health, safety and the environment produced at the university

1. The development of national safety and ergonomics standards; 2 . The office of ergonomics-related inventions and technologic activities; 3. Preparing environmental guidelines and protocols for training children; 4. The establishment of three corresponding international committees for standardization at the university; 5. Designing practical tools for using in the crisis, disasters, ergonomics, and so on; 6 . Designing the related software and applications; 7. Designing and manufacturing the application of "enhancing knowledge of disaster preparedness and response, ergonomics, biofeedback, and so on".

The strategic plan of the University of Social Welfare and Rehabilitation Sciences to use HSE

1. Educate Masters' students in the field of promoting HSE management in all social welfare aspects; 2 . Attention to the occupational dimensions of special populations of disabled (15\%), elderly, and children; 3. Focus on disabled employed people in the country (the rule of employing 3\% of the society); 4 . Attention to the social characteristics of the environment and environmental welfare; 5. More special attention to patient's safety in rehabilitation; 6. Considering occupational rehabilitation and the rehabilitation of injured in the fields of management and the quality of health services in the rehabilitation and social welfare; 7 . Presenting the new and 


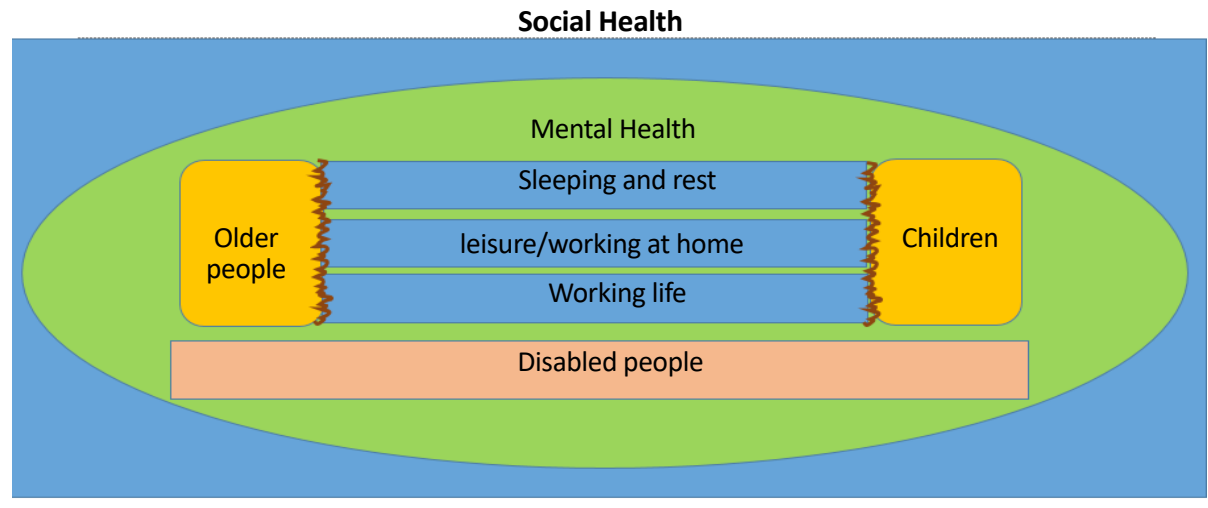

Figure 1. The HSE Model in Social Welfare and Rehabilitation Sciences

community-based approaches (the entire classes of the society) to the HSE Major.

The presentation of the model of All Hazard University approach to $\mathrm{HSE}$

1. Hazards for all ages and all people; 2 . A similar approach to schools HSE plan; 3. HSE in nursing homes, an elderly-friendly city, and so on; 4. HSE in people with disabilities, low abilities, and disabled (Figure 1).

\section{Discussion}

Overall, considering the key role of the UWRS in community health (including the environmental health and occupational health, and their improvement, as well as to prevent accidents and reduce injuries and disabilities by promoting safety at all levels of life and work), also its potential and extended range of activities in Tehran Province and city, as well as its crucial role and uniqueness in the country and the Middle East, it seems necessary to establish HSE management at this university because of its facilities and human resources that are operating in different departments, and integrating all the academic and administrative activities.

In addition, there is a lack of a coherent system for the management of these services in one of the medical universities affiliated to the Ministry of Health and Medical Education. Thus, there is a need for the establishment of HSE Major to achieve the long-term preventive goals and cultural development in the university and society; HSE Major works as a missing link to not only direct and coordinate all these matters but also is practical and useful. Also, more fundamental research and even the establishment and implementation of an integrated HSE management system in the communities covered by this university (low-ability and vulnerable groups) can be a source of community comfort and well-being, as well as the development of HSE field.

Other advantages of establishing HSE Major in the university include adding new areas of research and science in the field of management of rehabilitation services, with an emphasis on these principles, paying more attention to counseling and social work, and the growth of exceptional children in the field of occupation and its related risks; calling for more specialized occupational and controlling research in the auditory sector; presenting HSE approaches in nursing and care in medical settings.

Calling for attention to HSE in preschool centers and the care of children with disability, highlighting in-depth research in pre-schools and providing care for children with disabilities; and improving the welfare of all society members. Therefore, due to the importance of prevention and health issues in the fields of welfare and rehabilitation, we decided to take steps towards establishing HSE Management Major.

\section{Conclusion}

In general, there is a conflict between the occupational and guild position of some disciplines (occupational health and the environmental health and industrial safety, and some similar fields). Thus, it is suggested that this Major address the different health aspects of the whole society and not only the occupational environment. It is also recommended that attention is paid to the hazards of the workplace, and the lives of the elderly, and the disabled as other matters covered by this field in the community. 


\section{Ethical Considerations}

\section{Compliance with ethical guidelines}

The present sudy was conducted by paying special attention to the general of information and all the ethical codes in this regard. Ethical issues (Including plagiarism, informed consent, misconduct, data fabrication and/or falsification, double publication and/or submission, redundancy, etc.) have been completely observed by the authors.

\section{Funding}

This research did not receive any specifc grant from funding agencies in the public,commercial, or not-forproft sectors.

\section{Authors' contributions}

All authors contributed in preparing this article.

\section{Conflict of interest}

The authors declared no confict of interes.

\section{Acknowledgments}

We sincerely appreciate the honorable professors of the HSE Specialist Board, who kindly visited the facilities and capabilities of the University of Welfare and Rehabilitation Sciences. We kindly request them to support the health aspect of the university, which has been overlooked and to help us with their cooperation and guidance. We would like also to thank Dr. Farhad Tabatabaei Ghamsheh, the Deputy of the University Support and the Managing Director of Ergonomics Department, Dr. Mohammad Ali Hosseini and Dr. Sayed Habibollah Kovari, the Faculty Members of the Department of Rehabilitation Management, Dr. Jafarpishe, the University Health Technology Management, Dr. Mokhtari Nia and Mr. Oskooeezadeh, the Faculty Members of Ergonomics Department, as well as Dr. Basakha, the Faculty Member of Social Welfare Management Department, Ms. Najm-alSadat Mousavi and Dr. Ghasemi, the Faculty Members of the Department of Basic Sciences, and other people who have contributed to this project.

\section{References}

[1] Mardani S, Nasiripour AA, Nikoo Maram H, Behzadi MH, Mardani N. [The relationship between Job Satisfaction and
HSE performance of employees in a molding industry (Persian)]. Iran Occupational Health. 2013; 10(6):106-20.

[2] Hashempour R, Hosseinpour Ghahremanlou H, Etemadi S, Poursadeghiyan $\mathrm{M}$. The relationship between quality of work life and organizational commitment of Iranian emergency nurses. Health in Emergencies and Disasters. 2018; 4(1):49-54 [DOI:10.32598/hdq.4.1.49]

[3] Khandan M, Aligol MH, Shamsi M, Poursadeghiyan M, Biglari H, Koohpaei A. Occupational health, safety, and ergonomics challenges and opportunities based on the organizational structure analysis: A case study in the selected manufacturing industries in Qom Province, Iran, 2015. Annals of Tropical Medicine and Public Health. 2017; 10(3):606-11. [DOI: 10.4103/ATMPH.ATMPH_110_17]

[4] Edwards JA, Webster S. Psychosocial risk assessment: Measurement invariance of the UK health and safety executive's management standards indicator tool across public and private sector organizations. Work \& Stress. 2012; 26(2):130-42. [DOI:10.1080/02678373.2012.688554]

[5] Firoozi Chahak A, Beheshti MH, Poursadeghiyan M. Effect of health, safety, and environment management system training on safety climate in a mine in Yazd Province, Iran. Journal of Occupational Health \& Epidemiology. 2015; 4(4):198-204 [DOI:10.18869/acadpub.johe.4.4.198]

[6] Bahman Nia GhR. [Change management and its role in continuous improvement of HSE management systems (Persian)]. Rahbord. 2005; 1(4):1-15.

[7] Farshad AA, Khosravi Y, Alizadeh SS. [The role of HSE management system in improving health, safety and environment performance in an oil organization (Persian)]. Iran Occupational Health. 2006; 3(2):1-2.

[8] Edwards JA, Webster S, Van Laar D, Easton S. Psychometric analysis of the UK health and safety executive's management standards work-related stress indicator tool. Work \& Stress 2008; 22(2):96-107. [DOI:10.1080/02678370802166599]

[9] Khandan M, Vosoughi S, Azrah K, Poursadeghiyan M, Khammar A. Decision making models and human factors: TOPSIS and Ergonomic Behaviors (TOPSIS-EB). Management Science Letters. 2017; 7(2):111-8. [DOI:10.5267/j. msl.2016.11.008]

[10] Forum EP. Guidelines for the development and application of health, safety and environmental management systems. ex. New York: Exploration \& Production; 2014

[11] Khammar A, Khandan M, Veisi R, Hosseinighosheh SN Alimohammadi M, Poursadeghiyan M, et al. An epidemiological study of fatal and non-fatal industrial accidents in Semnan, Iran. Health in Emergencies and Disasters. 2019; 4(2):93-100. [DOI:10.32598/hdq.4.2.93]

[12] Amani S, Tahmasbi S, Baneshi A, Poursadeghiyan M, Karimzadeh $\mathrm{M}$. Factors affecting professional competency of Iranian preschool administrators based on crisis management approach. Health in Emergencies and Disasters Qurterly. 2018; 3(4):185-90 [DOI:10.32598/hdq.3.4.185]

[13] Almasi A, Dargahi A, Mohammadi M, Asadi F, Poursadeghiyan M, Mohammadi S, et al . Knowledge, attitude and performance of barbers about personal health and occupational Health. Archives of Hygiene Sciences. 2017; 6(1):75-80 [DOI:10.29252/ArchHygSci.6.1.75] 
[14] Khosravipour B. [Investigating the role of health, safety and environment management (MS-HSE) in reducing incidents (Persian)]. Paper presented at: National conference on passive defence \& sustainable development. 3-4 October 2016; Tehran, Iran

[15] Beheshti M. [Guide for the establishment and development of health, safety and environmental management system, specializing in oil and gas process industries (Persian)]. Tehran: Moravejan Bahrevari; 2007.

[16] Rahimizadeh A, Arjmandi R, Lahijanian AM. [Investigating the effect of HSE special training courses on employee's behavioral changing (Persian)]. National conference on new and creative thoughts in management, accounting, legal and social studies. 14 June 2018; Khoy, Iran.

[17] Padash A. [Establishing a Health, Safety and Environment management system (HSE) for the systematic development of projects (Persian)]. Paper presented at: National confer- ence on the development of the executive system of civil, industrial and urban development projects. 16-17 May 2007; Tehran, Iran.

[18] Supreme Council for the Planning of Medical Sciences. [Bachelor's degree program in health, safety and environment management, approved by the forty-sixth session of the Supreme Council for the Planning of Medical Sciences (Persian)]. Tehran: Ministry of Health and Medical Education; 2010.

[19] Nasiripour AA, Nikoomaram H, Tajoddini M. [The relationship between organizational culture and personnel HSE performance in a production company: A case study in Saipa car company (Persian)]. Journal of Health and Safety at Work. 2012; 2(3):71-84.

[20] Khammar A, Poursadeghiyan M, Marioryad H, Nabi Amjad R, Alimohammadi M, Khandan M. Patient safety climate and its affecting factors among rehabilitation health care staff of hospitals and rehabilitation centers in Iran-Tehran. Iranian Rehabilitation Journal. 2019; 17(1):39-48. [DOI:10.32598/ irj.17.1.39]

[21] Farajpour Khazai O, Pishyare E, Rassafani M, Bakhshi E, Poursadeqiyan $\mathrm{M}$. The relationship between areas of occupation and severity of depression, anxiety, and stress in Parkinson's disease (Persian)]. Archives of Rehabilitation. 2019; 20(2):190-201.

[22] Dargahi A, Farrokhi M, Poursadeghiyan M, Ahagh MM, Karami A. Evaluation of functional preparedness and non structural safety of different health units of Kermanshah University of Medical Sciences in coping with natural disasters. Health in Emergencies and Disasters Quarterly. 2017; 2(4):201-06. [DOI:10.29252/nrip.hdq.2.4.201]

[23] Kakavand MG, Rostami E, Poursadeghiyan M, Abbasi M, Omidianidost A, Avakh A, et al. Assessment of safety condition in one of the teaching hospitals in Kermanshah (2015): A case study. Archives of Hygiene Sciences Volume. 2016; 5(3): $245-53$.

[24] Karami A, Dargahi A, Farrokhi M, Poursadeghian M, Ivanbagha R, Mostafaei $\mathrm{P}$, et al. Studying the environmental health condition of the cities in the Kermanshah Province affected by 2017 earthquake. Health in Emergencies and Disasters. 2018; 4(1):29-36.[DOI:10.32598/hdq.4.1.29]

[25] Dargahi A, Bagheri S, Poursadeghiyan M, Hosseini Ahagh M M, Farrokhi M. Knowledge and attitudes of students in
Khalkhal medical sciences faculty on health actions in emergencies. Health in Emergencies \& Disasters Quarterly. 2017; 3(1):51-6. [DOI:10.29252/nrip.hdq.3.1.51]

[26] Biglari H, Hami M, Yari A, Poursadeghiyan M, Farrokhi M. Awareness of medical students of Gonabad University about nutrition and food preservation in disasters. Health in Emergencies \& Disasters Quarterly. 2017; 2(3):133-8. [DOI:10.18869/nrip.hdq.2.3.133]

[27] Miri A, Hami M, Dargahi A, Poursadeghiyan M, Farrokhi $\mathrm{M}$, Ivanbagha R, et al. Study on the awareness of the students of Azad University of Medical Sciences about nutrition and food storing stuff during crisis. Health in Emergencies and Disasters. 2018; 3(2):91-6. [DOI:10.29252/nrip.hdq.3.2.91] 